\title{
Avaliação Nutricional e Autopercepção Corporal de Praticantes de Musculação em Academias de Caxias do Sul - RS
}

\author{
Nutritional Assessment and Body Self-Perception of Bodybuilders \\ in Caxias do Sul - RS
}

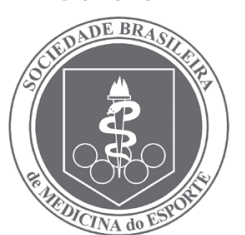

Artigo Original
Heloísa Theodoro

Simone Rufatto Ricalde

Francisco Stefani Amaro

Curso de Nutrição, Centro de Ciências Biológicas e da Saúde, Universidade de Caxias do Sul, Caxias do Sul, RS.

Endereço para correspondência: Heloísa Theodoro

Rua Prontolage, 87, Rio Branco 95096-630 - Caxias do Sul,RS, Brasil. Tels.: (54) 3226-2424, (54) 9195-6881. E-mail: helo_theodoro@hotmail.com

Submetido em 14/07/2008 Versão final recebida em 16/01/2009 Aceito em 30/01/2009

\section{RESUMO}

O objetivo deste estudo foi diagnosticar o estado nutricional e a autopercepção corporal de frequentadores de academias de Caxias do Sul. A amostra foi composta por 87 homens, na faixa etária entre 20 e 25 anos. Para o diagnóstico do estado nutricional foi feita a análise da adequação da ingestão de macronutrientes e micronutrientes - vitaminas A, C e E, cálcio, ferro, selênio e zinco, por meio do método recordatório de 24 horas, além da caracterização do perfil antropométrico e da autopercepção corporal, que foi avaliada através de um questionário com questões fechadas e escalas de silhuetas. Para análise estatística foram utilizadas análise descritiva e o teste $t$ de Student pareado. Valores de $p<0,05$ foram considerados significantes. Os resultados indicaram que a alimentação dessa população foi caracterizada como normoglicídica, hiperlipídica e hiperproteica; o consumo de suplementos foi de $29,9 \%$, sendo a maioria à base de proteínas. Quanto aos micronutrientes, mostrou adequação em selênio, zinco e ferro e inadequação em vitaminas A, C e E, e cálcio. Apenas $19,5 \%$ dos indivíduos ingeriram o recomendado desse mineral por dia. O percentual de gordura corporal dos praticantes de musculação (14,08 \pm 4,25\%) foi classificado como dentro da média. Em relação à autopercepção corporal, a maioria deseja ter uma silhueta igual a ou maior que a representada por um indivíduo eutrófico. Essa população apresenta importantes inadequações nutricionais, sendo ou não decorrente do objetivo de ganho de massa muscular, necessitando assim de orientação nutricional.

Palavras-chave: nutrição, composição e imagem corporal, frequentadores de academia.

\begin{abstract}
The aim of this study was to diagnose the nutritional status and self-perception of health club goers of Caxias do Sul. The sample was composed of 87 men, aged 20-25 years. The diagnosis of the nutritional status was determined through analysis of suitability of macronutrients and micronutrients - vitamin A, C and $\mathrm{E}$, calcium, iron, selenium and zinc by a 24h-questionnaire with closed questions and body silhouette scales. Statistical analysis was by descriptive analysis and paired Student's $t$ test. Significant values were $p$ $<0.05$. Results have shown that diet in this population was normoglycidic, hyperlipidic and hyperproteic; supplements consumption was of $29.9 \%$, being its majority protein-based. Concerning macronutrients, selenium, zinc and iron were suitable, and vitamins A, C and E and calcium were deficient. Only 19.5\% of the individuals ingested the calcium daily recommendation. The body fat percentage of the bodybuilding practitioners (14.08 $\pm 4.25 \%)$ was classified as within the average. Concerning body self-perception, most of the subjects want to have a silhouette equal or bigger than the eutrophic model. This population presents important nutritional inadequacies, being these derived or not from the aim to gain muscular mass. Therefore, it is necessary that it receives nutritional guidance.
\end{abstract}

Keywords: nutrition, body composition and image, health club goers.

\section{INTRODUÇÃO}

A prática regular e adequada de exercícios físicos melhora a qualidade de vida quando associada a uma dieta balanceada (1). A alimentação equilibrada é essencial na formação, reparação e reconstituição de tecidos corporais, mantendo a integridade funcional e estrutural do organismo, assim, tornando possível a prática de exercícios físicos ${ }^{(2)}$.

O início de um programa de atividade física tem como um dos principais motivos a insatisfação com o próprio corpo ou com a imagem que se tem dele ${ }^{(3)}$. O enfoque dado pela mídia em mostrar corpos atraentes leva a sociedade à valorização da aparência física idealizada, com aumento de músculos, estando sujeito a perder o ideal de corpo saudável( ${ }^{(4)}$. Os treinamentos de força tornam-se um meio eficaz de aumento de massa muscular ${ }^{(1)}$.

Praticantes de hipertrofia muscular possuem necessidades nutricionais diferenciadas das de indivíduos sedentários ou pouco ativos. Porém, o problema ocorre quando a preocupação de um indivíduo de que seu corpo seja pequeno ou franzino se torna excessiva, passando a ter um padrão alimentar específico, que geralmente é composto por dieta hiperproteica, além de inúmeros suplementos alimentares ou substâncias para aumentar o rendimento físico, sem a devida orientação, trazendo danos à saúde ${ }^{(5)}$. 
Tendo em vista a crescente busca de um corpo físico idealizado sem a devida preocupação com a saúde e qualidade de vida, o objetivo deste estudo foi identificar o padrão alimentar dos frequentadores de academias e sua adequação, descrever o perfil antropométrico e avaliar a percepção dos entrevistados sobre o próprio corpo.

\section{MÉTODOS}

Sujeitos: A amostra foi constituída de 87 homens selecionados aleatoriamente dentro dos seguintes critérios, idade entre 20 e 25 anos, com prática regular de exercícios de musculação havia no mínimo cinco meses, com duração igual ou superior a uma hora por sessão, em mais de três vezes por semana, de nove academias randomizadas aleatoriamente do total das estabelecidas em Caxias do Sul, RS.

Antes de qualquer intervenção os indivíduos foram convidados a participar do estudo e assinaram o TCLE - Termo de Consentimento Livre e Esclarecido. Este foi previamente aprovado pelo Comitê de Ética e Pesquisa da Universidade de Caxias do Sul sob parecer n 128/07.

Avaliação de autopercepção corporal: Aplicou-se o questionário (anexo 1) estruturado com perguntas fechadas, referente à percepção dos indivíduos frente a sua forma física. Juntamente, avaliou-se a autoimagem do indivíduo sobre sua silhueta, assim como a forma física que gostaria de ter através do conjunto de silhuetas propostas por Stunkard et al.(6). A pesquisadora principal explicou aos entrevistados que as silhuetas numeradas de 1 a 4 representam indivíduos com menor percentual de massa muscular, respectivamente; a silhueta de no 5 representa um indivíduo eutrófico, e as numeradas de 6 a 9 eram para ser interpretadas como homens, em escala, proporcionalmente, com aumento de massa muscular.

Anexo 1. Questionário de Autopercepção Corporal

A) Encontra-se satisfeito com sua aparência física atualmente?

1. ( ) Sim 2.( ) Não

B) A preocupação com sua forma física o leva a praticar mais exercícios?

1. ( ) Sim 2.( ) Não

C) Você tem medo de emagrecer?

1. ( ) Sim 2.( ) Não

D) Você tem medo de engordar?

1. ( ) Sim 2.( ) Não

E) Você compara seu físico com o de outros?

1. ( ) $\operatorname{sim}$ 2.( ) Não

F) Estar no mesmo ambiente que pessoas, as quais julga ser mais fortes que você, faz-Ihe sentir inferior?

1.( ) $\operatorname{sim}$ 2.( ) Não

G) Assinale com um " $X$ " a silhueta abaixo que representa sua aparência física atual. H) Circule a silhueta que você gostaria de ter.

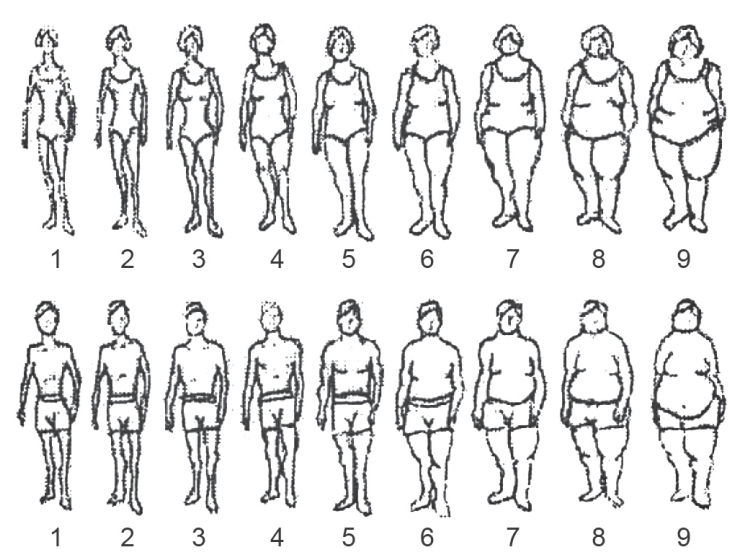

Figura 1. Sequências de silhuetas ${ }^{(5)}$, para avaliação de autopercepção corporal
Avaliação dietética: Utilizou-se o recordatório de 24 horas, pois o mesmo é de rápida aplicação e imediato período de recordação, condições que predispõem a maior participação ${ }^{(7)}$. Esse foi aplicado em único dia por participante, que variou de terças a sextas-feiras, sempre à noite, pela mesma pesquisadora. Para visualização das porções, utilizou-se registro fotográfico de medidas caseiras ${ }^{(8)}$. Para cálculo dos macronutrientes e micronutrientes foi utilizado o software Avanutri versão 3.0.

Avaliação do estado nutricional: Fez-se aferição do peso corporal através da balança digital (Acqua Plenna SIN 9190P) com sensibilidade de $100 \mathrm{~g}$ e capacidade para 180kg; o indivíduo posicionou-se em pé, no centro da base da balança, com os braços estendidos ao longo do corpo e descalço. Para obter-se a altura do sujeito utilizou-se o estadiômetro compacto tipo trena (Sanny ${ }^{\circledR}$ ES-2040), no qual o indivíduo ficou em pé, ereto, descalço, com os calcanhares juntos, costas retas, ombros e glúteos em contato com o estadiômetro, os braços estendidos ao lado do corpo, com a cabeça erguida olhando para um ponto fixo na altura dos olhos. Com a obtenção desses dados calculou-se o índice de massa corporal (IMC) e classificaram-se os indivíduos de acordo com critérios da Organização Mundial da Saúde ${ }^{(9)}$.

A aferição de pregas cutâneas foi realizada antes do treino, sendo feita três vezes em forma de circuito nas sete pregas avaliadas (peitoral, tricipital, subescapular, axilar média, suprailíaca, abdominal e coxa). Utilizou-se o plicômetro científico (Cescorf) com sensibilidade em milímetros. O protocolo utilizado foi descrito previamente por Jackson e Pollock ${ }^{(10)}$. O percentual de gordura foi calculado através do software Physical Test versão 4.1.15.

Análise estatística: As análises foram realizadas com auxílio do programa SPSS (Statistical Package for Social Sciences) versão 15.0. As mesmas incluíram: análise descritiva e o teste $t$ de Student pareado. Valores de $p<0,05$ foram considerados significantes.

\section{RESULTADOS}

Em relação aos dados antropométricos dos 87 frequentadores de academias avaliados, encontraram-se: idade média de 22,32 \pm 1,89 anos, peso médio de 74,92 $\pm 8,70 \mathrm{~kg}$ e estatura média de 1,75 \pm 0,06m.

$\mathrm{Na}$ tabela 1 encontram-se os dados antropométricos de IMC e de percentuais de gordura distribuídos conforme suas classificações. 0 valor médio encontrado para IMC foi de 24,25 $\pm 2,66 \mathrm{~kg} / \mathrm{m}^{2}$, sendo a média eutrófica, e para percentual de gordura, de 14,08 \pm 4,25, sendo classificada como média.

A tabela 2, referente à avaliação de calorias e macronutrientes da alimentação dos entrevistados, mostra que 57,5\% indivíduos possuem o valor energético total da dieta abaixo do preconizado para a prática de exercícios. Quanto aos macronutrientes, percebe-se um padrão alimentar hiperproteico, normoglicídico e hiperlipídico.

Tabela 1. Diagnóstico de IMC e \% de gordura dos frequentadores de academias

\begin{tabular}{|c|c|c|c|}
\hline & & Frequência & Percentual \\
\hline \multirow{4}{*}{ IMC } & Eutrofia & 54 & 62,1 \\
\hline & Sobrepeso & 30 & 34,5 \\
\hline & Obesidade grau I & 03 & 3,4 \\
\hline & Total & 87 & 100,0 \\
\hline \multirow{7}{*}{$\%$ de gordura } & Excelente & 01 & 1,1 \\
\hline & Bom & 33 & 37,9 \\
\hline & Acima da média & 10 & 11,5 \\
\hline & Média & 15 & 17,2 \\
\hline & Abaixo da média & 20 & 23,0 \\
\hline & Ruim & 08 & 9,2 \\
\hline & Total & 87 & 100,0 \\
\hline
\end{tabular}

Análise descritiva, percentuais de diagnóstico de IMC apresentados segundo critério de classificação da WHO(8) Classificaçăo de \% de gordura de acordo com Pollock e Willmore ${ }^{(11)}$. 
Tabela 2. Padrão de ingestão de macronutrientes dos frequentadores de academias

\begin{tabular}{l|c|c|c|c|c}
\hline \multicolumn{2}{l|}{} & SBME & Abaixo & Adequado & Acima \\
\hline & Média & Recomendação & Percentual & Percentual & Percentual \\
\hline Calorias (kcal/kg/dia) & $38,95 \pm 17,10$ & $37-41$ & 57,5 & 2,3 & 40,2 \\
\hline Proteínas (g/kg/dia) & $1,74 \pm 0,85$ & $1,4-1,8$ & 20,7 & 43,7 & 35,6 \\
\hline Carboidratos (g/kg/dia) & $4,99 \pm 2,37$ & $5-8$ & 24,1 & 64,4 & 11,5 \\
\hline Lipídios (g/kg/dia) & $1,40 \pm 0,76$ & $0,8-1,2$ & 20,7 & 36 & 44 \\
\hline
\end{tabular}

Análise descritiva, dados apresentados em média \pm desvio- padrăo. Percentuais apresentados de acordo com a recomendação da Sociedade Brasileira de Medicina do Esporte ${ }^{(12)}$.

Na tabela 3 verificou-se que a dieta dos praticantes de musculação estava adequada em selênio, zinco e ferro; abaixo das recomendações em vitaminas antioxidantes ( , C e E), e inadequada em cálcio; apenas 19,5\% dos indivíduos ingeriram o recomendado desse mineral por dia.

Tabela 3. Padrão de ingestão de micronutrientes dos frequentadores de academias

\begin{tabular}{|c|c|c|c|c|c|}
\hline & & DRI & Abaixo & Adequado & Acima \\
\hline & Média & Recomendação & Percentual & Percentual & Percentual \\
\hline Vitamina A ( $\mu \mathrm{g} / \mathrm{dia})$ & $633,06 \pm 521,84$ & $900-3000$ & 78,2 & 21,8 & 0,0 \\
\hline Vitamina C (mg/ dia) & $75,90 \pm 80,63$ & $90-2000$ & 67,8 & 32,2 & 0,0 \\
\hline Vitamina E (mg/ dia) & $17,55 \pm 19,63$ & $15-3000$ & 57,5 & 42,5 & 0,0 \\
\hline Selênio ( $\mu \mathrm{g} / \mathrm{dia}$ ) & $95,43 \pm 61,23$ & $55-400$ & 27,6 & 72,4 & 0,0 \\
\hline Zinco (mg/ dia) & $14,00 \pm 8,67$ & $11-40$ & 43,7 & 55,2 & 1,1 \\
\hline Ferro (mg/ dia) & $29,97 \pm 12,40$ & $8-45$ & 9,2 & 90,8 & 0,0 \\
\hline Cálcio (mg/ dia) & $653,94 \pm 514,83$ & $1000-2500$ & 80,5 & 19,5 & 0,0 \\
\hline
\end{tabular}

Análise descritiva, dados apresentados em média \pm desvio- padrăo. Percentuais apresentados de acordo com a recomendação da Dietary Reference Intakes (13)

A relação do consumo de suplementos alimentares com a média de ingestão de proteínas da dieta dos frequentadores de academia foi descrita na tabela 4. Consumiam suplementos alimentares 26 indivíduos, sendo a média de consumo de proteínas destes superior ao limite máximo recomendado, diferentemente dos que não consumiam, que possuíam a média de ingestão de proteínas adequada. Dos suplementos alimentares utilizados, 80,8\% eram à base de proteínas e apenas 19,2\% à base de carboidratos.

Tabela 4. Consumo de suplemento alimentar e a ingestão diária de proteínas dos frequentadores de academias

\begin{tabular}{l|c|c|c}
\hline & Suplemento alimentar & $N$ & Média \\
\hline $\begin{array}{l}\text { Ingestão diária de } \\
\text { proteínas (g/kg dia) }\end{array}$ & Sim & 26 & $2,07 \pm 1,04$ \\
\cline { 2 - 4 } & Não & 61 & $1,59 \pm 0,72$ \\
\hline
\end{tabular}

$\overline{\text { Análise através do teste } t \text { de Student, dados apresentados em média } \pm \text { desvio- padrão. Sendo estatisticamente }}$ significante $(P<0,05)$.

Na tabela 5 encontram-se os dados referentes à satisfação com a aparência física dos indivíduos entrevistados; a maioria $(63,2 \%)$ dos praticantes de musculação afirmou estar satisfeita com sua aparência física.

Tabela 5. Satisfação com aparência física dos frequentadores de academias

\begin{tabular}{l|c|c}
\hline & Frequência & Percentual \\
\hline Sim & 55 & 63,2 \\
\hline Não & 32 & 36,8 \\
\hline Total & 87 & 100,0 \\
\hline
\end{tabular}

Análise descritiva, dados apresentados em frequência e percentual de acordo com o total da amostra.
A relação entre a silhueta atual e a silhueta desejada é verificada na tabela 6 e no gráfico 1, que mostram a autopercepção corporal dos indivíduos estudados; de acordo com esses resultados verificou-se que os frequentadores de academia almejavam ter silhueta maior do que aquela que possuem. Os dados encontrados indicam que 65,5\% (57) desejam ter silhueta igual a ou maior que a representada por um indivíduo eutrófico.

Tabela 6. Auto- percepção corporal dos frequentadores de academias

\begin{tabular}{l|c|c}
\hline & N & Média \\
\hline Aparência física atual & 87 & $4,08 \pm 1,18$ \\
\hline Aparência física desejada & 87 & $4,77 \pm 0,96$ \\
\hline Análise atrásés do teste t de Student Pareado dados apresentados em média + desvio- padrão. Sendo estatisti-
\end{tabular}
camente significante $(\mathrm{P}<0,05)$.

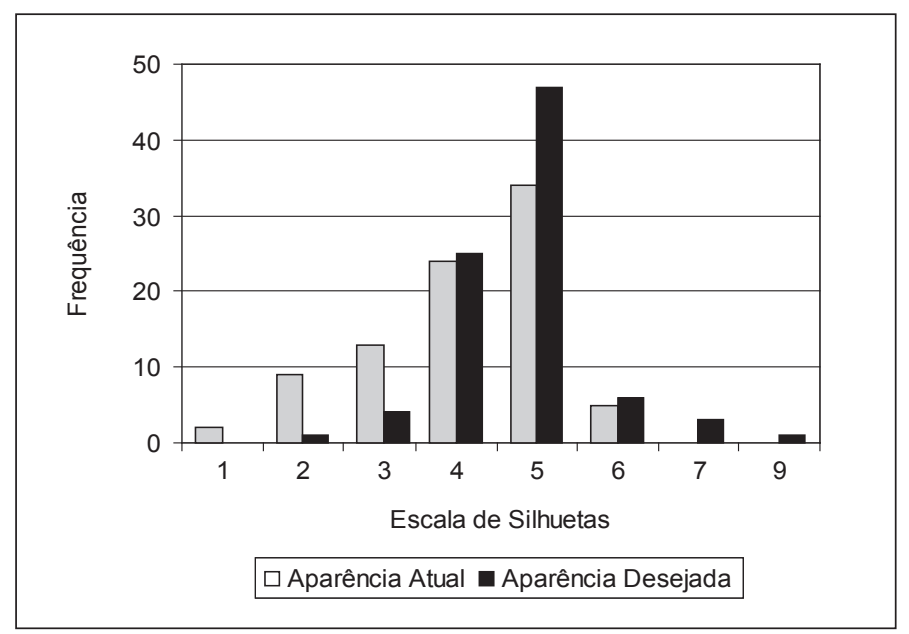

Gráfico 1. Comparação de escolha de silhuetas dos frequentadores de academias

\section{DISCUSSÃO}

O perfil antropométrico da população estudada foi considerado eutrófico. Sua alimentação foi caracterizada como normoglicídica, hiperlipídica e hiperproteica; adequada em selênio, zinco e ferro; abaixo do recomendado em vitaminas $\mathrm{A}, \mathrm{C}$ e $\mathrm{E}$, e cálcio. Os praticantes de hipertrofia muscular expressaram o desejo de possuir silhueta maior, podendo estar relacionado com algumas inadequações nutricionais.

Em relação aos dados antropométricos avaliados, observou-se que os praticantes de musculação apresentam-se dentro dos padrões de normalidade segundo a classificação do IMC e do percentual de gordura corporal. Semelhantemente, ao estudo com 32 frequentadores de academias com idade superior a $18 \operatorname{anos}^{(14)}$, que obtiveram IMC médio de 23,85kg/m². Martins e Santos ${ }^{(15)}$ estudaram 105 homens praticantes de atividade física por lazer e encontraram como médias IMC de $24,80 \mathrm{~kg} / \mathrm{m}^{2}$ e de gordura, $11,39 \%$.

Neste estudo verificou-se que 32,2\% dos indivíduos apresentaram percentual de gordura corpórea abaixo da média ou ruim, sendo um percentual elevado quando comparado com outros estudos; um dos fatores pode ser devido à dieta hiperlipídica encontrada em 44\% da população estudada, semelhantemente, ao trabalho que avaliou praticantes de exercícios físicos em academias de São Paulo(14), que encontrou dietas hiperlipídicas em 38,5\% dos indivíduos do sexo masculino. Para Polacow e Lancha ${ }^{(16)}$, a associação entre atividade física e dieta hiperglicídica e hipolipídica parece ter efeitos vantajosos sobre a composição e peso corporais, quando comparada com a associação exercício e dieta hiperlipídica.

Quanto à ingestão de carboidratos, 64,4\% dos entrevistados possuíam dieta normoglicídica; o consumo adequado desse macronutriente tem como objetivo a melhora da desempenho, uma vez que promove 
maiores estoques de glicogênio muscular e, consequentemente, maior tolerância ao esforço ${ }^{(16)}$. O mesmo foi encontrado em um estudo realizado com atletas levantadores de peso, com idade entre 16 e 23 anos ${ }^{(17)}$.

Duran et al. (14) apontaram maior percentagem de inadequação às recomendações proteicas entre os homens (69,3\%), não havendo indivíduos do sexo masculino com dietas hipoproteicas. Assim como no presente estudo, predominaram dietas hiperproteicas; 43,7\% estavam adequadas à recomendação e 35,6\% acima do preconizado para o exercício físico. Praticantes de musculação costumam ter alimentação rica em proteínas, muitas vezes, acima das recomendações, devido a modismos, falta de informações e orientação inadequadas ${ }^{(18)}$. Ressalta-se a importância da intervenção de profissionais capacitados para orientação e prescrição individualizada de consumo de proteínas.

Estudo realizado por Kantikas ${ }^{(19)}$ verificou que 52\% da população masculina fazem uso de suplementos nutricionais com objetivo de ganho de massa muscular. Em um estudo com 183 praticantes de musculação(20), 62 indivíduos (34\%) consumiam suplementos alimentares e os mais utilizados foram à base de proteínas e aminoácidos (49\%). No estudo atual, 22,6\% dos indivíduos consumiram suplementos alimentares e apresentaram consumo proteico acima do recomendado. A ingestão excessiva de proteína e aminoácidos, através dos alimentos ou suplementos proteicos, tem demonstrado efeitos danosos à saúde.

Para Philips(21), até o momento, não há nenhuma evidência para sugerir que suplementos proteicos são necessários para a otimização do crescimento muscular ou ganho de força, devido ao fato de que o estímulo para a síntese proteica aumenta a eficiência da utilização de proteínas, o que reduz as elevadas doses da dieta.

Em relação aos micronutrientes essenciais à prevenção do estresse oxidativo, no estudo realizado por Martins e Santos ${ }^{(15)}$ o consumo das vitaminas $A$ e $E$ foi inadequado; somente a vitamina $C$ atingiu a recomendação. Em estudo com 21 atletas de futebol(22), verificou-se que 70\% dos atletas do sexo masculino ingeriram quantidade insatisfatória de alimentos que contêm vitamina E e betacaroteno. Nesse estudo verificou-se inadequação de ingestão das vitaminas $A, C$ e E, estas importantes captadoras de radicais livres na prevenção de lesões celulares.

Quanto aos minerais envolvidos no sistema antioxidante do organismo, observou-se que consumo de selênio e zinco encontra-se dentro das recomendações. Semelhante ao estudo realizado por Donangelo et al. ${ }^{(23)}$, 55\% consumiam zinco de acordo com o requerido. Martins e Santos ${ }^{(15)}$ encontraram a ingestão de zinco adequada e a de selênio, acima da recomendação.

\section{REFERÊNCIAS BIBLIOGRÁFICAS}

1. Williams MH. Nutrição: para saúde, condicionamento físico e desempenho esportivo. 5.ed. São Paulo: Ed. Manole, 2002

2. Viebig RF, Nacif MA. Recomendações nutricionais para a atividade física e o esporte. Revista Brasileira de Educação Física, Esporte, Lazer e Dança 2006:1:2-14

3. Damasceno VO, Lima JRP, Vianna JM, Vianna VRA, Novaes JS. Tipo físico ideal e satisfação com a imagem corporal de praticantes de caminhada. Rev Bras Med Esporte 2005;11.

4. Russo R. Imagem corporal: construção através da cultura do belo. Movimento \& Percepção 2005;5.

5. Assunção SSM. Muscle dysmorphia. Revista Brasileira de Psiquiatria 2002;24.

6. Stunkard AJ, Sorenson T, Schlusinger F. Use of the Danish Adoption Register for the study of obesity and thinness. In: Kety SS, Rowland LP, Sidman RL, Matthysse SW, editors. The genetics of neurological and psychiatric disorders. New York: Raven, 1983;115-20.

7. Fisberg RM, Berzabeth S, Marchioni CML, Martini LA. Inquéritos alimentares métodos e bases científicas. São Paulo: Ed. Manole, 2005.

8. Registro Fotográfico para Inquéritos Alimentares. São Paulo: Ed. Metha, 2003.

9. World Health Organization. Obesity: preventing and managing the global epidemic. WHOTechnical Report Series; 894. Geneva, Switzerland, 2000.

10. Jackson AS, Pollock ML. Generalized equations for predicting body density of men. Br J Nutr 1978:40:497-504

11. Pollock M.; Willmore JH. Padrão de resultados de avaliação física por idade para o sexo masculino e feminino. Exercícios na Saúde e na Doença. Rio de Janeiro: Ed. Medsi, 1993.

12. Carvalho T. Diretriz da Sociedade Brasileira de Medicina do Esporte. Modificações dietéticas, reposiçäo hídrica, suplementos alimentares e drogas: comprovação de ação ergogênica e potenciais riscos para a saúde. Rev Bras Med Esporte 2003;9

13. Dietary Reference Intake. Disponível em: http://www.iom.edu/object.file/master/20/004/0.pdf

14. Duran ACFL, Latorre MRDO, Florindo AA, Jaime CP. Correlação entre consumo alimentar e nível de atividade física habitual de praticantes de exercícios físicos em academia. Rev Bras Ciên Mov 2004;12:15-19.

15. Martins FR, Santos JAR. Atividade física de lazer, alimentaçăo e composição corporal. Rev Bras Educ Fís Esp 2004;18:159-67.
Neste estudo, o cálcio foi o mineral com o menor consumo, ficando a ingestão abaixo do recomendado. Em um estudo realizado por Paschoal e Amâncio(24) observou-se que somente a metade da população atingiu a recomendação de cálcio e isso foi atribuído ao baixo consumo de leite e derivados. $\mathrm{O}$ alto consumo de proteínas pode promover balanço negativo de cálcio e induzir perda de massa óssea ${ }^{(25)}$. A redução de magnésio e cálcio no plasma pode produzir câimbras musculares intensas, devido a seu envolvimento no processo de contração muscular(26).

A tendência masculina de desejar um corpo com maior volume e menor quantidade de gordura corporal foi apontada em um estudo realizado com praticantes de caminhadas ${ }^{(3)}$, porém, é intensificada nos praticantes de musculação; pois em academias, em regra, desfilam corpos malhados, bem como outros que buscam alcançar tal status (27), assim demonstrado nos resultados apresentados; a maioria expressou o desejo de ter uma forma física maior do que aquela que possuíam. A valorização aguda de uma ética moralista e fugaz da aparência leva ao consumo exacerbado de alimentos dietéticos, práticas de exercitação física, dentre outros hábitos não condizentes com a manutenção de saúde ${ }^{(27)}$.

O atual estudo apresenta como limitação, a aplicação única do inquérito alimentar de recordatório de 24 horas, avaliando o consumo atual e não habitual de nutrientes. Esse instrumento apresenta boa reprodutividade, capaz de refletir a média de ingestão de energia e de todos os nutrientes avaliados. Porém, para calcular inadequação da ingestão de nutrientes, seria interessante utilizar aplicações repetidas desse inquérito alimentar, pois possibilita a diminuição da variabilidade intraindividual(28).

Outra limitação verificada foi a escassez de instrumentos sensíveis à avaliação de distorção de imagem corporal que enfatize a valorização de ganho de massa muscular excessiva e que permita a visualização das silhuetas corporais em planos diferentes.

Os dados obtidos no presente estudo apontam para a necessidade de um suporte de profissionais de nutrição em academias, tendo em vista que houve importantes inadequações nutricionais, que podem influir negativamente para saúde e objetivo do frequentador de academia.

Devido o baixo número de estudos disponíveis, sugerem-se mais pesquisas relacionando o perfil dietético com autopercepção corpórea nessa população, pois alterações de imagem corporal no sexo masculino, ao contrário do que se pensava, são quadros relativamente comuns e diferem do padrão de distorção tipicamente feminino ${ }^{(5)}$.

Todos os autores declararam não haver qualquer potencial conflito de interesses referente a este artigo.

16. Polacow VO, Lancha AH. Dietas hiperglicídicas: efeitos da substituição isoenergética de gordura por carboidratos sobre o metabolismo de lipídios, adiposidade corporal e sua associação com atividade física e com o risco de doença cardiovascular. Arq Bras Endocrinol Metab 2007;51.

17. Cabral CAC, Rosado GP, Silva CHOS, Marins JCB. Diagnóstico do estado nutricional dos atletas da Equipe Olímpica Permanente de Levantamento de Peso do Comitê Olímpico Brasileiro (COB). Rev Bras Med Esporte 2006;12.

18. Pereira RF, Lajolo FMA, Hirschbruch MD. Consumo de suplementos por alunos de academias de ginástica em São Paulo. Revista de Nutrição 2003;16.

19. Kantikas ML. Avaliação do uso de suplementos nutricionais à base de soro bovino pelos praticantes de musculação em academias de Curitiba- PR, 2007. 59f. [Dissertação (Mestrado)]. Universidade Federal do Paraná, Curitiba. 2007. http://dspace.c3sl.ufpr.br/dspace/bitstream/1884/12119/1/Disserta\%C3\%A7\%C3\%A30\%20Gra\%C3\%A7a.pdf

20. Araújo LR, Andreolo J, Silva MS. Utilização de suplemento alimentar e anabolizante por praticantes de musculaçăo nas academias de Goiânia-GO. Rev Bras Ciên Mov 2002;10.

21. Philips S. Protein requirement and supplementation in strength sports. Nutrition 2004;20:689-95.

22. Fanhani APG, Ferreira MP. Agentes antioxidantes: seu papel na nutrição e saúde de atletas. Rev Saúde e Biol 2006; 1:33-41.

23. Donangelo CM, Koury JC, Oliveira KJF. Micronutrientes e capacidade antioxidante em adolescentes sedentários e corredores. Revista de Nutrição 2007;20.

24. Paschoal VC, Amancio OM. Nutritional status of Brazilian elite swimmers. Int J Sport Nutr Exerc Metab 2004; 14:81-94.

25. Allen $\mathrm{HL}$, Oddoye EA, Margen S. Protein-induced-hypercalciuria: a long term study. American Journal of Clinical Nutricion 1979; 32:741-49

26. Maquirriain J, Merello MJ. Abordaje clínico del deportista con calambres musculares. Rev Asoc Argent Ortop Traumatol 2005;70:367-72.

27. Estevăo A, Bagrichevsky M. Cultura da "corpolatria"e body- building: notas para reflexão. Revista Mackenzie de Educação Física e Esporte 2004;3:13-25.

28. Barbosa KBF, Rosado LEFPL, Franceschini SCC, Priore SE. Instrumentos de inquérito dietético utilizados na avaliação do consumo alimentar em adolescentes: comparação entre métodos. ALAN 2007;57:43-50. 